\title{
Políticas públicas para formação de professores \\ e seus impactos \\ na educação básica
}

\author{
Marinalva Vieira Barbosa \\ Natália A. Morato Fernandes
}

As ações voltadas para a formação de professores estão inseridas nas políticas educacionais - este é um conceito amplo e engloba tudo aquilo que um governo faz ou deixa de fazer em e para a educação. Considerando educação como algo vasto, que acontece em diferentes espaços (família, igreja, comunidade, dentre outros), cabe destacar que as políticas educacionais abrangem também (e não só) a educação escolar que se procura oferecer para uma população de modo geral. Por isso, a formação de professores é um ponto fundamental no escopo das ações que um governo promove em busca das mudanças e/ou melhorias na educação escolar.

Diante disso, as políticas de formação de professores ganharam força e visibilidade nas últimas décadas em decorrência da concepção de que representam uma ação fundamental para a melhoria da educação básica. Desde 2007, a partir do lançamento do Plano de Desenvolvimento da Educação e do Plano de Metas Compromisso Todos pela Educação (Decreto n 6.094/2007), o Ministério da Educação (MEC) e a Coordenação de Aperfeiçoamento de Pessoal de Nível Superior (Capes) - que assumiu a condição de agência responsável pela proposição e desenvolvimento de ações para a formação de professores da educação básica - fizeram investimentos vultosos em programas e projetos com vistas à qualificação e valorização da docência. Foram focos desses investimentos a formação inicial e a formação continuada, nas modalidades presencial e a distância. 
De acordo com Montandon (2012), duas premissas sustentaram as ações decorrentes das políticas públicas voltadas para a melhoria da educação e, por consequência, para a formação de professores: a primeira é a de que tais ações precisam envolver a União, os estados e os municípios; a segunda é a de que sejam concebidas a partir da articulação entre MEC, instituições de educação superior (IES) e as escolas de educação básica. Decretos, resoluções e portarias que deram materialidade a essas políticas enfatizam de forma reiterada a necessidade de garantir a qualidade dos cursos de formação de professores, rompendo assim as dicotomias entre teoria e prática, ensino e pesquisa, escola e universidade e, principalmente, conhecimento científico e didático.

As formas de atuação/ação dos entes responsáveis pelas políticas para formação de professores foram, direta ou indiretamente, determinadas pela União. Também foram definidos os focos de atenção com vistas à melhoria da educação. Entretanto, após aproximadamente uma década do início dessas ações do governo federal, cabe indagar: Como estão sendo articuladas essas políticas? Quais impactos estão produzindo na formação de professores para a educação básica?

Diante desses questionamentos e considerando a dimensão dessas ações, nasceu a proposição deste número da revista Em Aberto sobre políticas públicas para formação de professores, enfocando os impactos do Programa Institucional de Bolsa de Iniciação à Docência (Pibid), do Pacto Nacional pela Alfabetização na Idade Certa (PNAIC), do Pacto Nacional pelo Fortalecimento do Ensino Médio (PNEM) e dos programas de mestrados profissionais - todos voltados para a valorização e incentivo à docência, a qualificação para o ensino na educação básica e o fortalecimento dos cursos de formação inicial e continuada nas instituições de ensino superior. Assim, a escolha desses programas se justifica porque, no momento em que foram implantados, representaram um importante investimento e, principalmente, um trabalho expressivo com o objetivo de promover mudanças em diversos níveis da educação. Além disso, são programas cujas ações abrangem diferentes níveis de formação inicial e continuada de professores para a educação básica.

Entendemos que publicizar reflexões sobre os resultados/impactos desses programas é relevante - considerando que as políticas públicas se efetivam por um processo que envolve decisão governamental, formulação, implantação e monitoramento/avaliação - pois, poderá trazer a público elementos importantes para se pensar a efetividade (em termos de alcance dos objetivos e metas), a continuidade ou o redirecionamento dessas políticas.

Por fim, cabe destacar que a formação inicial e continuada de professores ainda é fundamental e mantém um caráter emergencial - porque, conforme já dito, é a ação que dá condições para que os professores exerçam suas atividades nas escolas de forma a se chegar a uma educação eficiente e acessível para todos. Mostrar como essas políticas estão sendo realizadas significa trazer elementos fundamentais para reforçar (ou rever) as concepções que sustentaram sua criação e implementação. Significa jogar luz sobre sua relevância para se produzir melhoria na e para a educação. 
Tendo em vista a temática definida para este número, abrimos a seção Enfoque - Qual é a questão? com o artigo "Políticas públicas para formação de professores: Pibid, mestrados profissionais e PNEM", de Marinalva Vieira Barbosa e Natália A. Morato Fernandes. São analisados documentos oficiais, como decretos e portarias, e documentos orientadores dos programas Pibid, mestrados profissionais e PNEM, no intuito de identificar o perfil docente que tais ações visam construir, a possibilidade de estabelecer aproximações entre tais programas e as metas e objetivos do Plano Nacional de Educação (PNE) 2014-2024.

A seção Pontos de Vista traz artigos sobre quatro programas educacionais que se inserem na política de formação de professores desenvolvida no Brasil nos últimos anos, um artigo sobre a formação de professores em educação especial e um artigo sobre as políticas públicas para formação de professores na Costa Rica.

Os autores são professores pesquisadores de diferentes instituições de ensino superior das cinco regiões do Brasil, e a autora do artigo internacional é da Universidad Nacional de Costa Rica. Interessante observar que são docentes que estiveram/estão envolvidos com os programas e as políticas analisados e que se dedicam a eles não apenas para operacionalizá-los, mas também para refletir e produzir conhecimento acerca deles, promovendo, desse modo, a aproximação entre teoria-prática-produção de conhecimento.

O primeiro artigo da seção Pontos de Vista - abrindo o bloco de artigos que analisam os programas educacionais implementados recentemente no Brasil -, intitulado "Estudo sobre a recontextualização do Programa Institucional de Bolsa de Iniciação à Docência", de autoria de Gicele Maria Cervi (ForPibid; Furb) e Milena Engels de Camargo (Furb), examina os projetos institucionais do Pibid de três IES do estado de Santa Catarina, utilizando o método Abordagem do Ciclo de Políticas (ACP), conforme proposto por Stephen Ball. Nessa perspectiva, a análise evidencia que, "com influência da Portaria Capes no 96/2013, as IES desenvolveram seus projetos institucionais e apresentaram aproximações nos discursos propostos em questões como ações inovadoras, práticas interdisciplinares e envolvimento com tecnologias, o que faz parte dos objetivos do programa, porém, apresentaram novos textos e discursos".

O segundo artigo, "O questionário como instrumento para avaliar os impactos do Pibid: representações de professores, diretores e alunos em Uberaba, Minas Gerais", de Janaína Aguiar Mendes Galvão, Flávio Henrique Dias Saldanha, Maíra Sueco Maegava Córdula e Vera Lúcia Bonfim Tiburzio, origina-se de uma pesquisa realizada no período de 2014 a 2016 por um grupo professores (do qual os autores fazem parte) vinculados ao Pibid da Universidade Federal do Triângulo Mineiro (UFTM). O artigo toma como foco o questionário, um dos instrumentos de obtenção de dados utilizados na pesquisa. Os autores destacam os dados obtidos por meio desse instrumento para delinear o perfil dos participantes, sua contribuição para o planejamento das etapas consecutivas da pesquisa, com o uso de outros instrumentos, e o papel de atividade formativa que esse instrumento desempenhou para a equipe multidisciplinar de professores pesquisadores. 
O terceiro artigo, intitulado "Implantação do Pacto Nacional pela Alfabetização na Idade Certa em Sergipe: estratégias formativas e avaliadoras", de Silvana Aparecida Bretas (UFS) e José Ricardo de Carvalho (UFS), investiga os impactos desse programa ao longo dos três primeiros anos de realização. Os autores apresentam detalhes sobre a organização dessa experiência, observando se a formação continuada trouxe o empoderamento dos professores na ação de alfabetizar e se recriou novos processos metodológicos de ensino.

O quarto artigo, "Escola como locus da formação continuada e o Pacto Nacional pelo Fortalecimento do Ensino Médio: efeitos na vida dos professores", de autoria de Licínia Maria Correa (UFMG), Maria Amália de Almeida Cunha (UFMG), Teodoro Zanardi (PUC-MG) e Liliane Oliveira Palhares da Silva (UEMG), discute o impacto da formação continuada, viabilizada pelo PNEM, na prática docente. Este programa, assim como o PNAIC, constitui-se a partir da união de esforços de três entes federados: União, estados e municípios, por meio da atuação da Secretaria de Educação Básica (SEB) do MEC, das secretarias estaduais de educação e das universidades públicas federais e estaduais. No artigo, o PNEM é contextualizado em meio às recentes mudanças da educação básica e da legislação educacional, particularmente para essa etapa de ensino. Os autores tomam como universo empírico o processo de formação coordenado e executado pela Universidade Federal de Minas Gerais (UFMG), no biênio 2014-2015.

No quinto artigo, "Requalificação e resistência: o que o Profletras nos diz de um futuro que já chegou", de Thomas Massao Fairchild (UFPA), discute-se a relação entre docência e conhecimento no Mestrado Profissional em Letras (Profletras). Para tanto, o autor analisa documentos normativos e textos acadêmicos produzidos por alunos do programa, visando refletir sobre questões relacionadas à forma e ao conteúdo dos produtos gerados a partir dessa formação. O autor problematiza o modelo de formação pautado na separação entre concepção e execução do trabalho de ensino, destacando a existência, por um lado, de mecanismos de controle sobre o tipo de produção almejado e, por outro lado, de possíveis estratégias de resistência a tal controle nas produções dos alunos.

O sexto artigo, intitulado "Reflexões a partir do entrecruzamento de vozes sociais presentes no discurso de egressos do mestrado profissional", de Abigail Vital (Cefet-RJ) e Andreia Guerra (Cefet-RJ), tem como objetivo apresentar uma análise discursiva do entrecruzamento de vozes sociais que contribuem para a realização da prática docente dos professores da educação básica egressos de mestrados profissionais. O foco da reflexão recai sobre os impactos dessa formação na construção da autonomia e autoria desses egressos quando estão no exercício da docência.

O sétimo artigo, "Formação de professores em educação especial no 'Plano Nacional de Educação Proposta da Sociedade Brasileira', de 1997", de autoria de Mariana Luzia Corrêa Thesing, Ana Paula dos Santos Ferraz, Bruna de Assunção Medeiros e Fabiane Adela Tonetto Costas - pesquisadoras da Universidade Federal de Santa Maria (UFSM) -, tem por objetivo problematizar alguns elementos das políticas públicas referentes à formação de professores da educação especial. Por meio da pesquisa documental, realiza a análise do Plano Nacional de Educação 
Proposta da Sociedade Brasileira, de 1997, e propõe um diálogo entre as diretrizes para a formação dos profissionais da educação previstas nesse documento e os encaminhamentos mais recentes sobre a formação de professores no País, dentre estes, os de educação especial.

Fechando a seção Pontos de Vista, temos o artigo "Políticas públicas relacionadas con la formación de profesores en Costa Rica", de Silvia García Vargas (UNA). O texto apresenta, por meio de análise documental e revisão bibliográfica, um estudo sobre o que tem sido feito na Costa Rica em matéria de formação docente, a partir da década de 1990. Tais iniciativas são examinadas mediante a legislação educacional do país, trazendo também referências ao contexto socioeconômico nacional em que essas políticas se inserem, bem como algumas influências internacionais. Em que pese a especificidade da experiência desse país centroamericano, algumas similaridades poderão ser percebidas em relação à realidade brasileira.

A seção Espaço Aberto está composta por duas entrevistas realizadas por Fernanda Borges de Andrade com Helder Eterno da Silveira, da Universidade Federal de Uberlância (UFU) e Maria Beatriz Luce, da Universidade Federal do Rio Grande do Sul (UFRGS).

Helder Eterno da Silveira fala sobre como, quando e porquê surgiu o Pibid e traça um panorama a partir de sua experiência como coordenador institucional desse programa na UFU e, posteriormente, como coordenador geral de programas de valorização do magistério da Capes. Enfatiza, principalmente, a capacidade de o Pibid possibilitar a formação profissional em contextos reais e não apenas a partir de uma construção teórica sobre a escola, desafio importante e fundamental para a profissão docente na atualidade.

Maria Beatriz Luce discute a questão da política de formação de professores e a concepção que perpassa as Diretrizes Curriculares de Formação de Professores, que estão sendo implantadas no País. Trata-se de um tema central que envolve não somente as universidades, mas as secretarias municipais e estaduais de educação, e promove a oportunidade de uma configuração federativa e participativa na formulação de políticas educacionais.

Na seção Resenhas, Thiago Antônio de Oliveira Sá (Unifal) analisa a coletânea Acesso e sucesso no ensino superior: uma sociologia dos estudantes, publicada em 2015, organizada pelas professoras da Universidade Federal do Rio de Janeiro (UFRJ) Gabriela Honorato e Rosana Heringer. De acordo com o resenhista, trata-se de uma obra resultante de uma agenda de pesquisa pujante, que tem como sujeitos de pesquisa os estudantes universitários de origens populares, num contexto nacional de expansão da oferta de vagas no ensino superior. A temática geral da obra são os efeitos empiricamente observados das políticas para democratização do acesso e da permanência na graduação, como as medidas de expansão de instituições, cursos e vagas e as ações afirmativas para estudantes de baixa renda oriundos das escolas públicas e para afrodescendentes.

A segunda resenha, feita por Amanda Regina Gonçalves (UFTM), apresenta a coletânea Reflexões sobre as experiências do Pibid na Udesc, organizada por Rosa 
Elisabete M. W. Martins e Luciana Rossato, ambas professoras nos cursos de licenciatura e, respectivamente, coordenadoras de área dos subprojetos de geografia e história do Pibid da Universidade do Estado de Santa Catarina (Udesc), em Florianópolis. De acordo com a resenhista, o livro evidencia um avanço nas políticas públicas direcionadas à formação de professores no Brasil e, portanto, representa um movimento de produção de conhecimento específico do período atual nas licenciaturas brasileiras, especificamente sobre a formação inicial de professores.

Na seção Bibliografia Comentada, organizada por Natália A. Morato Fernandes e Marinalva Veira Barbosa, indicam-se obras relacionadas a políticas públicas para a formação de professores. Diante de um tema tão abrangente e com produção significativa, essa seleção buscou privilegiar obras publicadas recentemente e com abordagem a partir de distintas áreas do conhecimento. Para tanto, as organizadoras contaram com a colaboração de professores que atuam nos cursos de licenciatura da UFTM e ajudaram a selecionar e comentar as obras.

Em suma, considerando que as reflexões presentes nos artigos, as entrevistas e as resenhas têm como foco pesquisas realizadas sobre diferentes programas e políticas voltados para a formação de professores, entendemos que esta publicação contribui com importantes elementos para uma análise mais avalizada sobre os desdobramentos dessas políticas nos estados, nos municípios, entre as IES que atuam na implementação dessas ações nas escolas e dentro de suas próprias propostas de formação inicial e continuada. São reflexões que, pela base teórica diversa que as sustentam, também trazem olhares diferentes para os resultados, efeitos e impactos dessas políticas (e as pesquisas delas derivadas) como produção de conhecimento sobre a formação inicial e continuada.

Marinalva Vieira Barbosa

Natália A. Morato Fernandes

Organizadoras

\section{Referência bibliográfica}

MONTANDON, M. I. Políticas públicas para a formação de professores no Brasil: os programas Pibid e Prodocência. Revista da ABEM, v. 20, n. 28, p. 47-60, 2012. Disponível em: <http://www.abemeducacaomusical.com.br/revistas/revistaabem/ index.php/revistaabem/article/viewFile/103/86> . Acesso em: 15 maio 2017. 